\title{
Properties of Reactive Materials for Application in Runoff Water Treatment Systems
}

\author{
Joanna Fronczyk \\ 1 Institute of Civil Engineering, Warsaw University of Life Sciences - SGGW, Nowoursynowska 159, \\ 02-776 Warsaw, Poland \\ e-mail: joanna_fronczyk@sggw.edu.pl
}

\begin{abstract}
The emissions related to urbanized areas, including communication routes and accompanying facilities, are considered as essential sources of subsoil pollution. Enhancement of the naturally occurring removal processes in infiltration systems, e.g. through placing the appropriately selected materials (treatment zones) on the flow path of runoff water, prevents the spread of undesirable components. The article presents the analysis of tests checking the properties of selected low-cost mineral materials, activated carbon and zero-valent iron in terms of their applicability in the runoff water treatment zones. Their physical features, surface structure, and chemical and hydraulic properties were analysed. The test results indicate a well-developed surface area of active carbon and halloysite, as well as an extensive pore volume of active carbon, halloysite, zeolite and diatomite. Nevertheless, the average pore diameters indicated the potential limited access of pollutants to the inner structure of all analyzed materials. The chemical parameters point to the stimulation potential of precipitation processes by limestone sand and silica spongolite, ion exchange by zeolite and silica spongolite, and oxidation-reduction processes by zero-valent iron. The value of the material hydraulic conductivity may potentially limit their application in infiltration systems. Taking into account all analyzed parameters, activated carbon together with silica spongolite and zeolite have the best application potential.
\end{abstract}

Keywords: infiltration system, contaminants removal, physico-chemical properties, hydraulic properties

\section{INTRODUCTION}

Systematic increase in area of economically used land is closely correlated with the increase of impermeable surfaces, on which progressively larger volumes of runoff water are generated. Water carries the pollutants emitted during the exploitation of urban areas (heavy metals, organic compounds, mainly petroleum substances and polycyclic aromatic hydrocarbons, biogens, dissolved salts, and suspensions) that, consequently, are driven to water receivers, e.g. to the soil/water system (Nawrot and Wojciechowska 2018). Currently, the runoff water is a problem not only due to its volume, but also its quality. Thus, it is important both to manage the runoff water in accordance with the principles of sustainable development in order to increase its local retention, as well as to protect all components of the environment. As such, special elements of the drainage system, e.g. separators, settlers, filter strips and swales, infiltration systems and wetlands, can be installed to ensure the appropriate quality of the runoff water discharged into the environment (Hilliges et al. 2013, Xu et al. 2020). Particularly noteworthy are the solutions treated as one of the elements of best management practice (BMP), known as permeable treatment zones (elements of infiltration systems) filled with the specially selected natural and synthetic materials (Fronczyk 2017, Valencia et al. 2020). The initial selection of materials involves the analysis of basic laboratory tests. However, the choice of the material, or possibly several materials constituting a mixture or forming a layered system, should be made considering the type of contaminants, their concentration and form (state) at which they are present in the natural environment.

In addition to the parameters directly characterizing the sorption rate and capacity of 
materials, which include, e.g. the maximum sorption capacity and constant reaction rates, there are a number of techniques that allow drawing indirect conclusions on the suitability of a given material for its use in the treatment of aqueous solutions. These include the analysis of material morphology, material surface chemistry, hydrophobicity, textural properties, crystalline structure, physicochemical parameters and hydraulic properties (Tran et al. 2017).

Scanning electron microscopy (SEM) allows for the observation of the surface and sub-surface areas on nano- and micrometric scales, and when the test is combined with the analysis of X-ray energy dispersion (EDS) - also the observation of the chemical composition (Stokes, 2008). On the basis of SEM images, one can conclude on the material porosity, the pore specific surface area, the shape and dimensions of pores, and the occurrence of specific forms such as nanotubes characteristic of halloysite. The SEM images, together with BET specific surface area, total pore volume, as well as micro- and mesopore volume allow drawing conclusions on the sorption capacity of materials and the availability of pores for the interaction with specific contaminants (Yong and Muligan 2004). Additionally, a larger percentage of micropores in the total pore volume may have a positive effect on the sorption capacity of materials in relation to small particles of contaminants (Tran et al. 2017). The pore dimensions play a significant role in the classification of some materials (e.g. zeolites, including primarily synthetic zeolites, and activated carbon) as molecular sieves that are used in the selective retention of chemical molecules (Shimizu et al. 2018). Moreover, the surface properties influence the cation exchange capacity (CEC) related to the quantity of negatively charged sites on the surface that retain exchangeable cations $\left(\mathrm{Na}^{+}\right.$, $\mathrm{K}^{+}, \mathrm{Ca}^{2+}$ and $\mathrm{Mg}^{2+}$ ). According to Khorshidi and $\mathrm{Lu}$ (2017), learning about this property of the material primarily facilitates the assessment of the processes responsible for removing contaminants as a result of ion exchange, but also implies water sorption, hydraulic conductivity and contaminant migration. On the other hand, the mineralogical composition determines the $\mathrm{pH}$ and oxidation-reduction potential (ORP) of a given material, which controls not only the ionic state of the functional groups on the surface of reactive materials that take part in binding contaminants, but also the speciation of heavy metals affecting their availability, precipitation, complexation by ligands, hydrolysis and redox reactions (Lodeiro et al. 2006).

The grain-size distribution of materials plays an important role in controlling the velocity of the contaminated water flow and thus the efficiency of treatment processes, because it influences hydraulic conductivity - a parameter defining the ability of a porous medium to conduct liquids. However, the parameter may be affected by many other factors, such as mineral composition, degree of saturation, porosity, as well as the shape and texture of the surface of solid particles (Head and Epps 2011). Parylak et al. (2013) indicated lower values of hydraulic conductivity for the materials characterized by a complex shape and surface structure compared to the materials with uniform shapes (glass balls), which was explained by the retention of larger amounts of water bound in microcavities. Likewise, the empirical Kozeny-Carman equation for the hydraulic conductivity of porous media (Carman 1937, Kozeny 1927) links this parameter with the porosity and specific surface area related to the volume of the medium. The results of calculations presented by Yong and Mulligan (2004) show a negative correlation between the specific surface area of the porous medium and the value of hydraulic conductivity.

To summarize, the properties of materials mentioned above determine both the treatment processes and the efficiency of contaminant removal in the soil/water environment, and thus may play a significant role in the treatment of the runoff water generated in urbanized areas. The primary objective of this study was to examine the materials (commonly referred to as reactive materials) that could be used as structural layers enhancing the processes of contaminant removal, naturally occurring in the soil/water environment. The paper presents an assessment of the selected reactive materials resulting in the preparation of a materials ranking for their potential application as the filling material of treatment zones in runoff water treatment systems.

\section{MATERIALS AND METHODS}

\section{General characteristics of selected materials}

Assuming the contaminant mixture in the runoff water from road infrastructure, the study 
focused on the properties of the following materials: zero-valent iron - ZVI (iPutec GmbH \& Co. KG, Rheinfelden, Germany), activated carbon (Activated Carbon Research and Production Plant, Mrozy, Poland), zeolite (N. Hrabovci, Zeocem S.P., Bystre, Slovakia), silica spongolite ("Góra Maćkowa" deposit, Polskie Górnictwo Skalne Minerał, Wrzosówka, Poland), limestone sand (Chatkowice deposit, Przedsiębiorstwo Górniczych "SILESIA" Sp. z o.o., Czechowice-Dziedzice, Poland), diatomite ("Jawornik Ruski" deposit, Specialist Mining Enterprise "Górtech", Wieliczka, Poland) and halloysite ("Dunino" deposit, PTH Intermag, Gliwice, Poland). Most of the selected materials belong to the group of natural minerals available in Poland, which are used, e.g., in the treatment technologies of the water and soil environment (Figarska-Warchoł et al. 2015, Radziemska and Mazur 2017, Radziemska 2018). Only zeolite came from a deposit located in Slovakia, because in Poland there are only deposits of clinoptilolite-montmorillonite clay, in which the content of clinotylolite is less than 30\% (Kłapyta and Żabiński 2008). Additionally, activated carbon and zero-valent iron were selected as reference materials due to their wide use in groundwater treatment with the permeable reactive barrier (PRB) method (Gillham and O'Hannesin, 1994, Feng et al., 2016). It is also worth mentioning that these reference materials are expensive compared to common mineral materials. The retail prices (per $100 \mathrm{~kg}$ ) of activated carbon and ZVI are 1050 PLN and 750 PLN, respectively, while for mineral materials - in the range of 11 PLN (silica spongolite) to 150 PLN (diatomite). Therefore, mineral materials can be called low-cost materials; thus, in consequence, their application may be of great importance when designing systems for treating runoff water from urban areas due to the installation costs.

\section{Test methods}

The test methods of the physicochemical properties, surface structure and the hydraulic properties of the reactive materials are presented in Figure 1. The tests of physicochemical and hydraulic properties were carried out in at least three repetitions, based on which the average values were calculated.

\section{TEST RESULTS}

\section{Physical properties and surface structure}

The most complex surface with a porous character has the activated carbon sample, while the least complex pore structure has the ZVI sample (Figure 2a), which is also reflected in the smallest specific surface of this material (Figure 3a). SEM images have also indicated a moderately developed surface of diatomite, zeolite and halloysite, as well as a poorly developed surface of silica spongolite and limestone sand.

On the basis of the results of nitrogen adsorption/desorption tests, the tested materials can be subdivided into three groups: (1) microporous material - activated carbon with a total specific surface area of $782.67 \mathrm{~m}^{2} / \mathrm{g}$ and a micropore surface area of $366.41 \mathrm{~m}^{2} / \mathrm{g}$; (2) mesoporous materials with moderately developed specific surface - diatomite with a specific surface area of $29.32 \mathrm{~m}^{2} / \mathrm{g}$, zeolite with a specific surface area of $33.34 \mathrm{~m}^{2} / \mathrm{g}$, and halloysite with a specific surface area of $48.33 \mathrm{~m}^{2} / \mathrm{g}$ (Fronczyk and Mumford 2019); (3) non-porous materials - silica spongolite $\left(2.82 \mathrm{~m}^{2} / \mathrm{g}\right)$ (Pawluk and Fronczyk 2015), limestone sand $\left(0.91 \mathrm{~m}^{2} / \mathrm{g}\right)$, and zero-valent iron $\left(0.52 \mathrm{~m}^{2} / \mathrm{g}\right)$ (Fronczyk 2017) (Figure 3a). The characteristics of the porous structure based on the average pore size (Figure $3 \mathrm{~b}$ ) allow the materials to be arranged in descending order of pore diameter as follows: zeolite $>$ halloysite $>$ ZVI $>$ limestone sand $>$ silica spongolite $>$ diatomite $\geq$ activated carbon. The maxima on the diagram of pore volume distribution (Figure $2 \mathrm{~b}$ ) show the presence of micropores at $0.41 \mathrm{~nm}$ and $0.5 \mathrm{~nm}$ in diameter for activated carbon and mesopores at $4.02 \mathrm{~nm}$ in diameter for diatomite, at about $4 \mathrm{~nm}$ and in the range of 7.5-20 nm in diameter for zeolite, and at $4 \mathrm{~nm}$ and $6 \mathrm{~nm}$ in diameter for halloysite. The values of pore volume and pore volume distribution (PVD) of silica spongolite, limestone sand and zero-valent iron have indicated a negligible number of pores, or lack thereof.

The test of mineral composition by diffraction analysis showed the amorphous character of activated carbon and the complementation of this material by quartz. The main mineral group containing diatomite is the silica group (chalcedony/ CT-opal) with clay minerals represented by smectite, illite, kaolinite, feldspar and quartz, which allows the material to be classified petrographically as diatomaceous earth. Silica spongolite and 


\begin{tabular}{|c|c|c|}
\hline \multirow{7}{*}{ 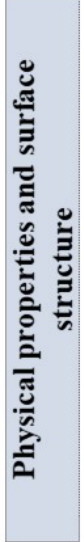 } & surface morphology & scanning electron microscopy (FEG Quanta 250, USA) \\
\hline & specific surface area & \multirow{3}{*}{$\begin{array}{l}\text { nitrogen adsorption at } 77 \mathrm{~K} \text {, } \\
\text { BJH method (ASAP } 2020 \mathrm{M} \text { Micromeritics, USA) } \\
\text { for activated carbon: t-Plot micropores analysis and } \\
\text { Horvath-Kawazoe method for micropores volume } \\
\text { distribution }\end{array}$} \\
\hline & pore diameters & \\
\hline & $\begin{array}{l}\text { total pore volume } \\
\left(\mathrm{V}_{\text {total }}\right)\end{array}$ & \\
\hline & mineral composition & 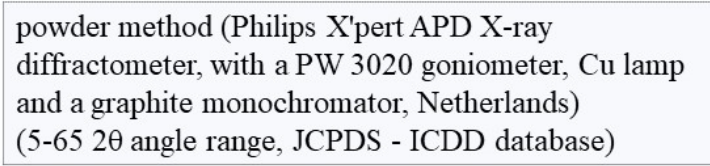 \\
\hline & specific density & pycnometric method (PN-EN ISO 17892-3:2016-03) \\
\hline & $\begin{array}{l}\text { particle size } \\
\text { distribution }\end{array}$ & $\begin{array}{l}\text { sieve and arometric methods (PN-EN ISO 17892- } \\
4: 2017-01 \text { ) }\end{array}$ \\
\hline \multirow{3}{*}{ 䓂 } & oxide composition & $\begin{array}{l}\text { energy dispersive X-ray fluorescence XRF (Epsilon-3 } \\
\text { spectrometer (Panalytical), Rh X-ray tube ( } 9 \mathrm{~W}, 50 \mathrm{kV} \text {, } \\
1 \mathrm{~mA}), 4096-\text {-channel spectrum analyzer, } 6 \text { measuring } \\
\text { filters }(\mathrm{Cu}-500, \mathrm{Cu}-300, \mathrm{Ti}, \mathrm{Al}-50, \mathrm{Al}-200, \mathrm{Ag}) \text { and the } \\
\text { highresolution solid state SDD detector }(50 \mathrm{~lm} \text { thick } \\
\text { beryllium window), cooled with a Peltier's cell }\end{array}$ \\
\hline & $\begin{array}{l}\text { electrolytic } \\
\text { conductivity, } \mathrm{pH}, \\
\text { and ORP }\end{array}$ & $\begin{array}{l}\text { in aqueous suspensions in the proportions } 1: 2.5(\mathrm{w} / \mathrm{v}) \\
\text { and } 1: 5(\mathrm{w} / \mathrm{v}) \text { respectively using a multi-parameter } \\
\text { meter } \mathrm{pH} / \mathrm{LF} 12 \text { (Schott, Germany) }\end{array}$ \\
\hline & $\begin{array}{l}\text { cation exchange } \\
\text { capacity }\end{array}$ & $\begin{array}{l}\text { at } \mathrm{pH} 7 \text { with ammonium acetate (Schollenberger and } \\
\text { Dreibelbis 1930) }\end{array}$ \\
\hline \multirow{2}{*}{ 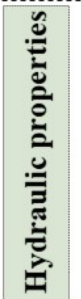 } & $\begin{array}{l}\text { hydraulic } \\
\text { conductivity }\end{array}$ & $\begin{array}{l}\text { constant gradient method }(\mathrm{i}=1.8) \text { using tap water } \\
\text { at } 15^{\circ} \mathrm{C} \text {, converting the results for a standard } \\
\text { temperature of } 10^{\circ} \mathrm{C}(\mathrm{ASTM} \text { D7100 }-11(2020))\end{array}$ \\
\hline & hydrophobicity & $\begin{array}{l}\text { based on the water drop penetration time, } \\
\text { interpretation based on the threshold times (Roberts } \\
\text { and Carbon 1971) }\end{array}$ \\
\hline
\end{tabular}

Figure 1. Scheme of the methodology used in this study

limestone sand can be assigned to the limestone group of minerals because of calcite $\left(\mathrm{CaCO}_{3}\right)$ being the main mineral component. Halloysite was confirmed to be the main component of the mineral from the "Dunino" deposit, together with goethite, hematite and microcline. The main component of the selected zeolite is clinoptilolite with admixtures of quartz and illite. The test results for zero-value iron illustrated the homogeneity of this material in mineralogical terms (Fe).

The tests confirmed that the lightest material is activated carbon $\left(\rho_{\mathrm{s}}=1.96 \mathrm{Mg} / \mathrm{m}^{3}\right)$ and the heaviest is zero-valent iron $\left(\rho_{\mathrm{s}}=7.80 \mathrm{Mg} / \mathrm{m}^{3}\right)$ (Figure 4a). Among mineral materials, diatomite was characterized by the lowest specific density, and limestone and silica spongolite by the highest density, for which this parameter had the same value. The specific density of mineral materials (in the range of 2.17 to $2.71 \mathrm{Mg} / \mathrm{m}^{3}$ ) allows classifying them as ordinary aggregates. A probable explanation is the similar origin, similar crystal structure, as well as surface morphology and oxide composition of these materials.

\section{Chemical properties}

The oxide composition of the reactive materials is presented in Figure 5. In the activated carbon sample, in addition to the predominant component, i.e. carbon, silicon dioxide $\left(\mathrm{SiO}_{2}\right)$ was observed, followed by aluminum oxide $\left(\mathrm{Al}_{2} \mathrm{O}_{3}\right)$, iron (III) oxide $\left(\mathrm{Fe}_{2} \mathrm{O}_{3}\right)$, calcium oxide $(\mathrm{CaO})$ and sodium oxide $\left(\mathrm{Na}_{2} \mathrm{O}\right)$. Zero-valent iron consists of iron (III) oxide, which accounts for $98.95 \%$. The percentage of the remaining components was lower than $1 \%$. The dominant component of halloysite and zeolite was silicon dioxide followed by aluminum oxide and additionally iron (III) 
(a)
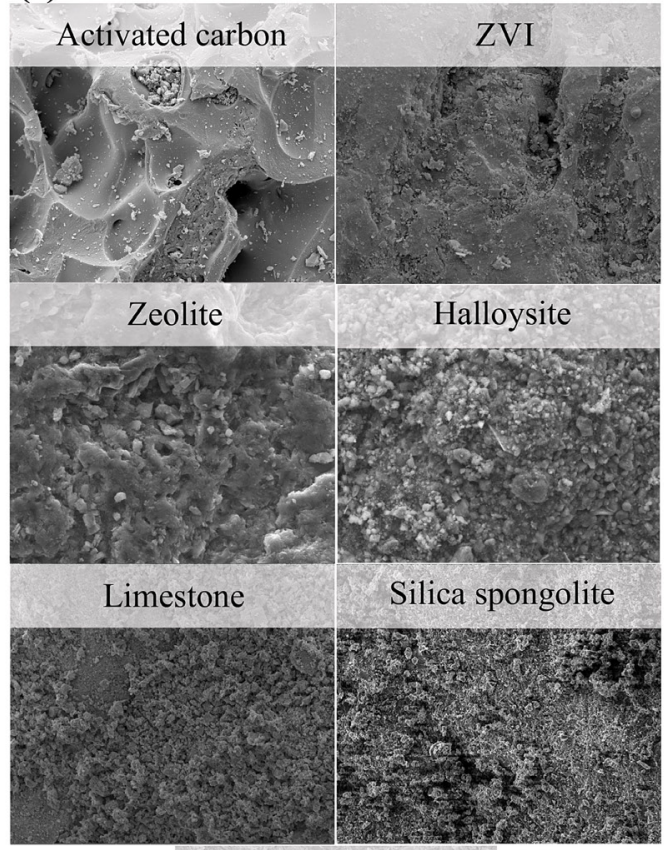

Diatomite

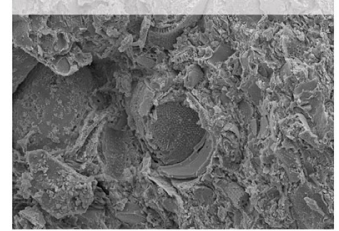

(b)
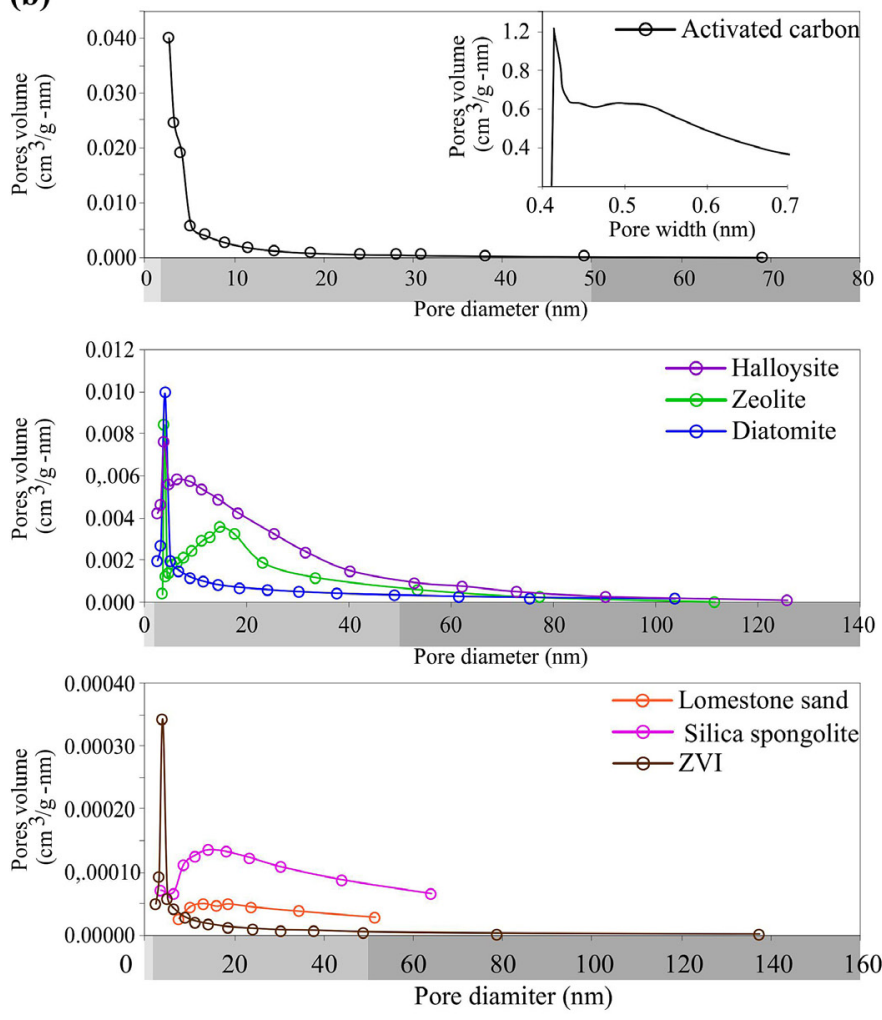

micropores

macropores

Figure 2. SEM images (2000 x magnification) (a), and distribution of pore volume relative to their diameter (additionally, for activated carbon, the distribution of micropore volume relative to their width) (b)
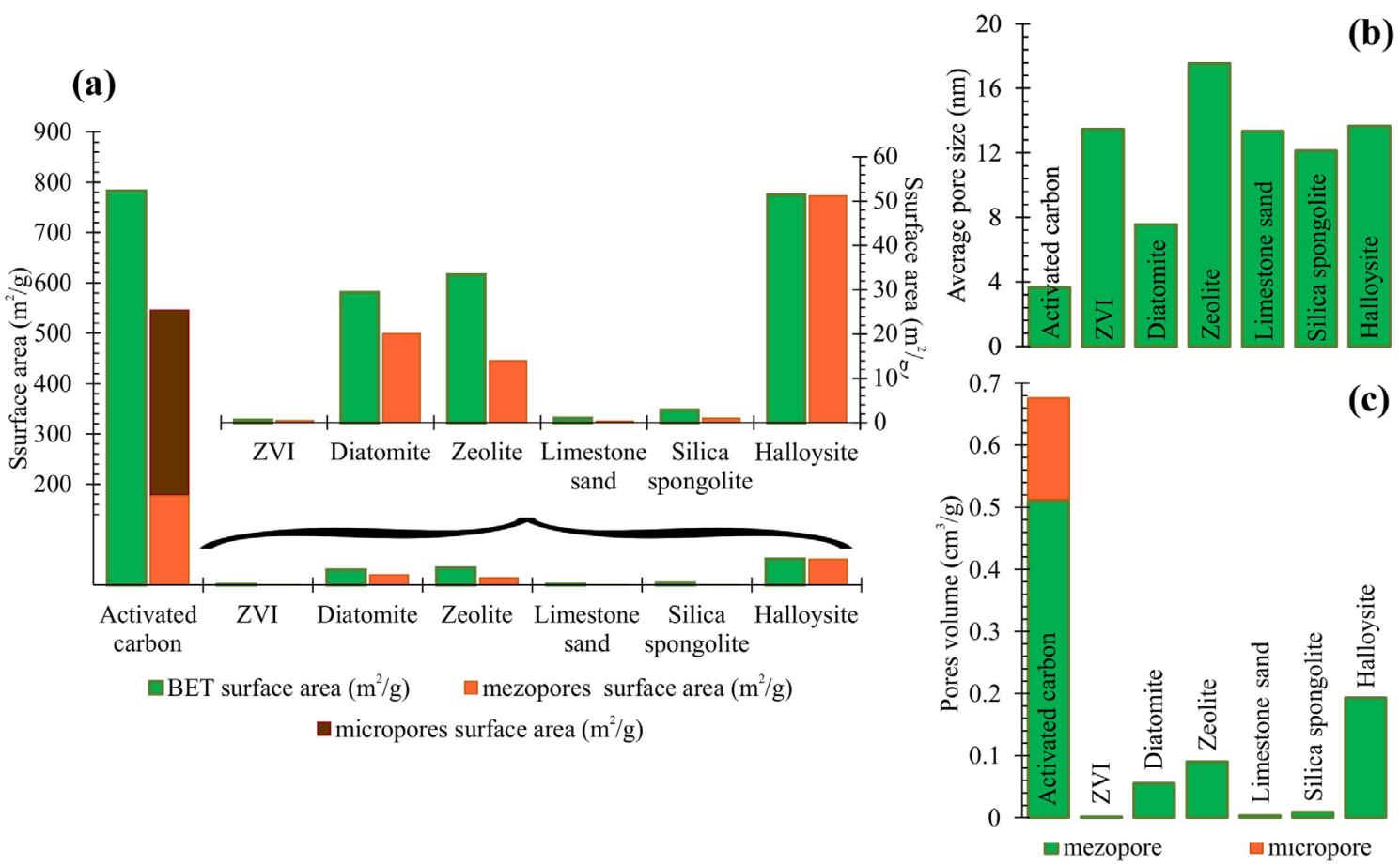

Figure 3. Specific surface area (a), average pore size (b), and pore volume (c) of the reactive materials tested 
(a)

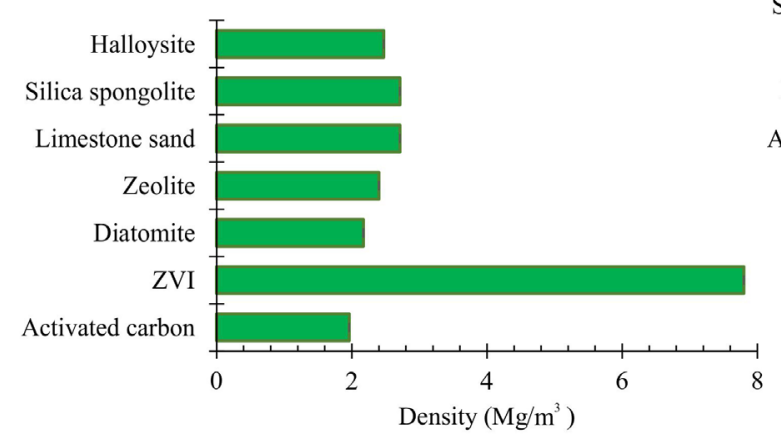

(b)

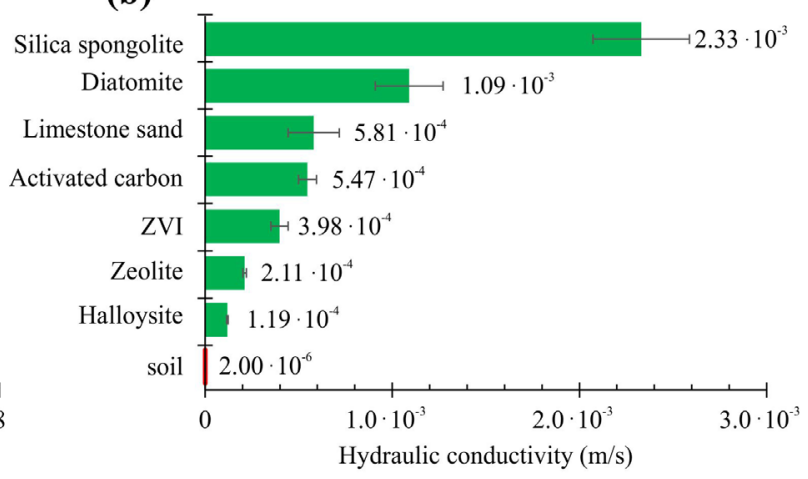

Figure 4. Average specific density values (a), and hydraulic conductivity (b) (mean value and standard deviation for $\mathrm{n}=5$ )

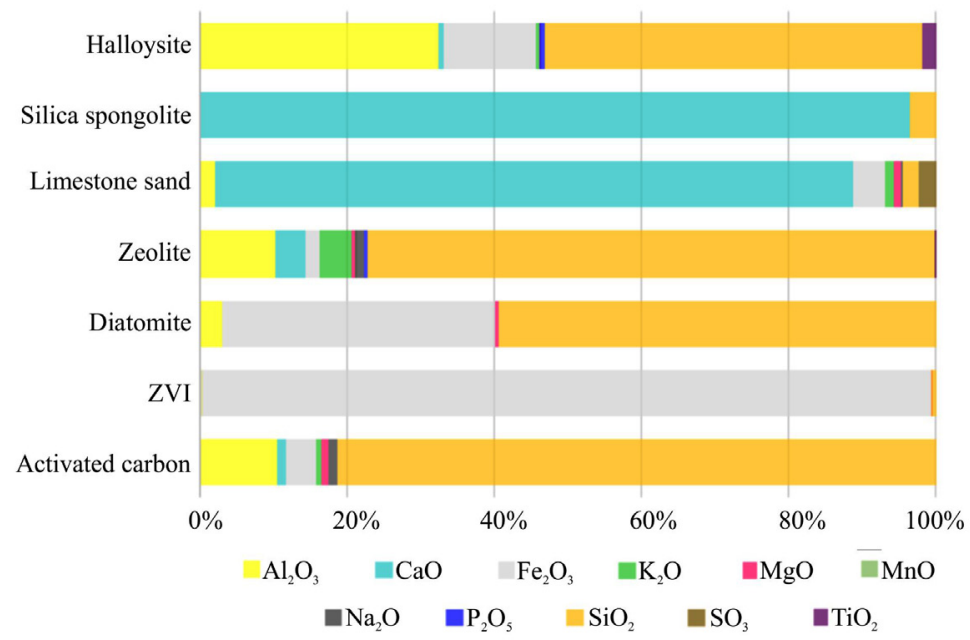

Figure 5. Oxide composition of the reactive materials tested

oxide for diatomite. Zeolite in its oxide composition contained over $1 \%$ of $\mathrm{K}_{2} \mathrm{O}, \mathrm{CaO}$ and $\mathrm{Fe}_{2} \mathrm{O}_{3}$, halloysite - of $\mathrm{Fe}_{2} \mathrm{O}_{3}$ and $\mathrm{TiO}_{2}$, and diatomite - of $\mathrm{Al}_{2} \mathrm{O}_{3}$ and $\mathrm{C}_{2} \mathrm{O}$. The studies on the oxide composition of limestone sand and silica spongolite also indicated the similarity of these materials. The main component of these materials is calcium oxide $(\mathrm{CaO})$, which accounts for $82.54 \%$ in limestone sand and $96.5 \%$ in silica spongolite. Limestone sand (above 1\%) additionally includes
$\mathrm{Fe}_{2} \mathrm{O}_{3}, \mathrm{SiO}_{2}, \mathrm{SO}_{3}$ and $\mathrm{Al}_{2} \mathrm{O}_{3}$, while silica spongolite contains also $\mathrm{SiO}_{2}$.

The reactive materials tested are characterized by a wide range of $\mathrm{pH}$, from slightly acidic $(\mathrm{pH}=6-7)$ in the case of diatomite and halloysite, through slightly alkaline $(\mathrm{pH}=7-8)$ for zeolite, silica spongolite and ZVI, to alkaline $(\mathrm{pH}>8)$ for limestone sand and activated carbon (Table 1), which is influenced by the mineralogical composition of the materials. The (slightly) alkaline $\mathrm{pH}$ of silica spongolite and limestone sand is influenced

Table 1. The $\mathrm{pH}$, electrical conductivity, oxidation-reduction potential, and cation exchange capacity of the reactive materials tested

\begin{tabular}{|c|c|c|c|c|c|c|c|}
\hline Parameter Material & $\begin{array}{c}\text { Activated } \\
\text { carbon }\end{array}$ & $\mathrm{ZVI}$ & Diatomite & Zeolite & $\begin{array}{l}\text { Limestone } \\
\text { sand }\end{array}$ & $\begin{array}{c}\text { Silica } \\
\text { spongolite }\end{array}$ & Halloyzite \\
\hline $\mathrm{pH}$ & $8.68^{*}$ & 7.85 & $6.48^{*}$ & $7.2^{*}$ & $8.27^{*}$ & 7.74 & $6.58^{*}$ \\
\hline $\mathrm{EC}(\mu \mathrm{S} / \mathrm{m})$ & $0.620^{*}$ & 0.068 & $0.103^{*}$ & $0.187^{*}$ & $0.095^{*}$ & 0.518 & $0.270^{*}$ \\
\hline ORP after $24 \mathrm{~h}(\mathrm{mV})$ & 74.7 & -29.5 & 184.6 & 79.1 & 50.3 & 83.3 & 141.3 \\
\hline CEC (meq/100g) & $5.97^{*}$ & - & $13.88^{*}$ & $118.02^{*}$ & $1.11^{*}$ & 77.61 & $10.76^{*}$ \\
\hline
\end{tabular}

* Fronczyk and Mumford 2019 
by the content of calcium carbonates, while that of activated carbon is likely to be the activation using base reagents. The determined values of electrolytic conductivity of the materials also show a large variation in the range from $0.068 \mu \mathrm{S} / \mathrm{m}$ for ZVI to $0.620 \mu \mathrm{S} / \mathrm{m}$ for activated carbon (Table 1). Out of the mineral materials, limestone sand has the lowest electrolytic conductivity $(0.095 \mu \mathrm{S} / \mathrm{m})$ and the largest - silica spongolite $(0.518 \mu \mathrm{S} / \mathrm{m})$. Moreover, the ORP of all mineral materials and activated carbon had positive values, only ZVI had a negative value of this parameter.

\section{Particle size and hydraulic properties}

On the basis of the particle size distribution tests, the characteristic values of effective diameters $\left(d_{10}, d_{50}\right.$ and $\left.d_{90}\right)$, coefficient of uniformity $\mathrm{C}_{\mathrm{U}}\left(\mathrm{d}_{60} / \mathrm{d}_{10}\right)$ and coefficient of curvature $\mathrm{C}_{\mathrm{C}}\left(\mathrm{d}_{30}{ }^{2} /\left(\mathrm{d}_{10} \cdot \mathrm{d}_{60}\right)\right)$ were determined (Table 2$)$. The mineral materials tested were created as a result of mechanical fragmentation of the rocks, which is why they are characterized by grains with sharp edges and rough surfaces. The largest variability in particle size was observed in silica spongolite (from 0.2 to $3.15 \mathrm{~mm}$ ) and the lowest - in halloysite, zeolite and limestone sand (from 0.2 to $1.0 \mathrm{~mm}$ ). It also reflects the percentage of fractions smaller than $0.5 \mathrm{~mm}$, on the basis of which materials can be arranged in the following increasing order: diatomite $<$ activated carbon $\approx$ zero-valent iron $<$ silica spongolite $<$ zeolite $<<$ halloysite $<$ limestone sand. Additionally, capillary rise was determined on the basis of the material particle size distribution using the equation for pure water $h_{c}=15.3 / r$, where $r$ is the mean pore radius $(\mathrm{mm})$. According to Dullien (1979), the mean pore radius can be calculated as $0.4 \cdot \mathrm{d}_{50} / 2$. The calculated capillary rise (Table 2) was between 41.6 (for activated carbon and diatomite) and $159.4 \mathrm{~mm}$ (for limestone sand), which corresponds to the content of particles smaller than $0.5 \mathrm{~mm}$.

The values of hydraulic conductivity determined for the reactive materials tested ranged from $1.19 \cdot 10^{-4} \mathrm{~m} / \mathrm{s}$ to $2.33 \cdot 10^{-3} \mathrm{~m} / \mathrm{s}$ (Figure $4 \mathrm{~b}$ ). The highest value of this parameter was observed for silica spongolite, a material with the widest range of particle sizes, and the lowest for halloysite. Interestingly, limestone sand was characterized by a higher hydraulic conductivity compared to activated carbon, ZVI, zeolite and halloysite, despite the fact that this material has the highest percentage of fractions smaller than $0.5 \mathrm{~mm}$.

The hydrophobicity tests based on the droplet soaking time allowed characterizing all analyzed materials as hydrophilic materials (Table 2), while according to the hydrophobicity classification presented by Doerr et al. (2000) the materials are included in the class of wettable materials. For all materials tested, the measured time was shorter than 1 second, only for activated carbon it was equal to 1.5 seconds. It is worth mentioning that the tests were performed for the materials dried at $100^{\circ} \mathrm{C}$ to reflect the least favorable conditions, because dry soils have the strongest hydrophobicity.

\section{DISCUSSION OF THE TEST RESULTS}

On the basis of the test results, the materials were assessed in terms of their potential suitability for use as filling material in the treatment zone enhancing removal processes within infiltration systems. The materials were compared only among each other; in this evaluation they were not compared to other materials that were not characterized in this paper. Therefore, each feature was normalized into the scoring range of 0

Table 2. Hydrophobicity and other characteristics determined from particle size distribution

\begin{tabular}{|c|c|c|c|c|c|c|c|}
\hline Parameter Material & $\begin{array}{l}\text { Activated } \\
\text { carbon }\end{array}$ & ZVI & Diatomite & Zeolite & $\begin{array}{l}\text { Limestone } \\
\text { sand }\end{array}$ & $\begin{array}{c}\text { Silica } \\
\text { spongolite }\end{array}$ & Halloyzite \\
\hline $\mathrm{d}_{10}(\mathrm{~mm})$ & 0.77 & 0.6 & 1.12 & 0.43 & 0.28 & 0.60 & 0.27 \\
\hline $\mathrm{d}_{50}(\mathrm{~mm})$ & 1.84 & 0.77 & 1.84 & 0.70 & 0.48 & 1.34 & 0.59 \\
\hline $\mathrm{d}_{90}(\mathrm{~mm})$ & 1.89 & 0.90 & 2.69 & 0.90 & 0.66 & 2.40 & 0.90 \\
\hline $\mathrm{C}_{\mathrm{u}}$ & 1.90 & 1.33 & 1.90 & 1.74 & 1.89 & 2.65 & 2.37 \\
\hline $\mathrm{C}_{\mathrm{C}}$ & 0.89 & 0.88 & 0.67 & 0.97 & 0.83 & 0.67 & 0.88 \\
\hline $\begin{array}{l}\text { Range of particle size } \\
(\mathrm{mm})\end{array}$ & $0.20-2.00$ & $0.40-2.00$ & $0.63-3.15$ & $0.20-1.00$ & $0.20-1.00$ & $0.2-3.15$ & $0.2-1.0$ \\
\hline Content of $\mathrm{d}<0.5 \mathrm{~mm}(\%)$ & 3.0 & 3.1 & 0 & 13 & 53 & 4.3 & 42 \\
\hline Hydrophobicity (s) & 1.5 & $<1.0$ & $<1.0$ & $<1.0$ & $<1.0$ & $<1.0$ & $<1.0$ \\
\hline Capillary rise $h_{c}(\mathrm{~mm})$ & 41.6 & 99.4 & 41.6 & 109.3 & 159.4 & 57.1 & 129.7 \\
\hline
\end{tabular}


to 1 . The number of scores (S) for the individual reactive material and particular feature was calculated from the following formula:

$$
S=\frac{(a-\min )}{(\max -\min )}
$$

where: $a$ - parameter value for a given material; min and max - the least and most desirable value of the parameter.

The ranking value (RV) was calculated as the average number of scores for all features. Screening of the tested reactive materials taking into account the analyzed parameters showed activated carbon as the material that best meets the analyzed criteria (Figure 6). Among the mineral materials, most points were assigned to silica spongolite and zeolite.

When analyzing surface structure, it is important to emphasize the large diversity both among all materials and in the group of mineral materials themselves. It is commonly believed that the sorption capacity of materials increases along with the specific surface area, which is also influenced by the pore volume, mainly due to the fact that adsorption is a surface process (Huang et al. 2015, Kumar et al. 2019, Yong and Muligan 2004). This applies to both organic and inorganic substances present in the runoff water. Consequently, it may be supposed that the largest amount of contaminants will be removed via adsorption on activated carbon and, from mineral materials, on halloysite. In addition, the pore dimensions and their arrangement determine the availability of pores and the type of contaminants removed by adsorption, because they act as a "sieve" allowing the molecules with given sizes to "enter" into the material structure (Tran et al. 2017). Kumar et al. (2019) pointed out that the diffusion processes of contaminants may be affected by pore size as well, influencing at the same time the kinetics of the adsorption processes. For example, the phosphate molecule has a diameter of about $0.48 \mathrm{~nm}$ (Tawfik and Viola 2011), the ammonium cation has a diameter of $0.350 \mathrm{~nm}$, copper, the empirical atomic diameters of zinc and nickel are equal to $0.270 \mathrm{~nm}$ and the empirical atomic radiuses of lead amount to $0.350 \mathrm{~nm}$ (Slater 1964). Taking into account the diameters of the mentioned inorganic contaminants and the dimensions of the pores of reactive materials, it can be assumed that contaminants once adsorbed in micropores can block other contaminants from accessing the pores. According to Huang et al (2015), larger volume of micropores results in greater surface area of the material, but also in lower mass transfer and adsorption rate. It should be noted that for adsorption processes, well-developed micropores are important, while macropores allow contaminants to penetrate deep into the material structure (Kłapyta and Żabiński 2008). It can be concluded that the best potential in terms of contaminant removal via adsorption processes has activated carbon - the material with the best developed surface area of micro- and mesopores, and the lowest - ZVI. In addition, halloysite structures with characteristic nanotubes and a zeolite molecular sieve structure deserve attention. These materials are also characterized by the best developed specific surface and the largest pore volume among the analyzed mineral materials. On the other hand, Kumar et al. (2019) proved that pores of diameters exceeding $10 \mathrm{~nm}$ play a crucial role in improving the adsorption kinetics. Thus, the average pore diameter of zeolite, limestone sand, silica spongolite and halloysite may imply good adsorption kinetic characteristics of these materials. When assessing the materials for this feature,

\begin{tabular}{|c|c|c|c|c|c|c|c|c|}
\hline & & ZVI & $\mathrm{AC}$ & $\mathbf{Z}$ & SS & D & $\mathrm{H}$ & LS \\
\hline \multirow{8}{*}{ 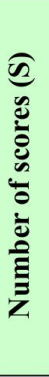 } & \multirow{8}{*}{$\begin{array}{r}\text { Specific surface area } \\
\text { Total pore volume } \\
\text { Average pore size } \\
\mathrm{pH} \\
\text { Oxidation-reduction potential } \\
\text { Cation exchange capacity } \\
\text { Hydraulic conductivity } \\
\text { Capillary raise }\end{array}$} & 0 & 1 & 0.042 & 0 & 0.037 & 0.065 & 0 \\
\hline & & 0 & 1 & 0.133 & 0.012 & 0.080 & 0.286 & 0.30 \\
\hline & & 0.706 & 0 & 1 & 0.609 & 0.281 & 0.719 & 0.698 \\
\hline & & 0.782 & 1 & 0.611 & 0.753 & 0 & 0.447 & 0.892 \\
\hline & & 1 & 0.513 & 0.493 & 0.473 & 0 & 0.202 & 0.627 \\
\hline & & 0 & 0.051 & 1 & 0.658 & 0.118 & 0.091 & 0.009 \\
\hline & & 0.126 & 0.194 & 0 & 1 & 0.439 & 0 & 0.209 \\
\hline & & 0.501 & 1 & 0.425 & 0.868 & 1 & 0.252 & 0 \\
\hline & Ranking value (RV) & 0.389 & 0.595 & 0.463 & 0.547 & 0.243 & 0.258 & 0.305 \\
\hline
\end{tabular}

Figure 6. Ranking of the reactive materials based on the tested properties 
the highest average pore size value (Figure 6) was considered to be the most convenient, which was related to the availability of pores for a larger spectrum of pollutants.

The analysis of crystalline and polycrystalline substances, as well as determination of the phase composition allow predicting the physicochemical interactions between the solid particles and contaminants present in water. Since carbonate minerals are considered to be good adsorbents of phosphate and heavy metals, and the presence of calcite influences the $\mathrm{pH}$ of the solid/water environment (Yong and Muligan 2004), the mineralogical composition of limestone sand and silica spongolite may suggest the dominant role of sorption processes in runoff water treatment. Additionally, kaolinite, halloysite, zeolite and hematite were used as adsorbents of some metal ions (Ahmed et al. 2013, Gruszecka-Kosowska et al. 2017, Inglezakis et al. 2018), while halloysite with induced positive charge was applied as an adsorbent of e.g. orthophosphate, sulfate and nitrate (Matusik 2014). The mineralogical composition closely affects the $\mathrm{pH}$ of a solid/water system, which is the most important control of metal partitioning (Yong and Muligan 2004). Considering the contaminants present in the road runoff water, the $\mathrm{pH}$ value may influence the treatment processes, especially of heavy metals, but also of ammonium ions. The $\mathrm{pH}$ value higher than 7 will result in the conversion of ammonium ions into the form of gaseous ammonia, while heavy metals will precipitate primarily in the form of hydroxides $(\mathrm{Pb}$ at $\mathrm{pH}>$ 7; $\mathrm{Cu}$ at $\mathrm{pH}>7.5 ; \mathrm{Zn}$ at $\mathrm{pH}>8.7$; $\mathrm{Ni}$ at $\mathrm{pH}>9.8$ ). It can therefore be expected that in the case of the contact between runoff water containing $\mathrm{Pb}$ and $\mathrm{Cu}$ with active carbon, $\mathrm{ZVI}$, limestone sand and silica spongolite, precipitation will play a significant role in the process of removing these contaminants, while ammonium ions will be released in a gaseous form to a variable extent. When comparing the materials, it was assumed that higher $\mathrm{pH}$ values result in better conditions for the runoff water treatment. However, it should be noted that this assumption is also associated with certain problems, for example ammonia will be released into the pore air and the precipitated heavy metals will be present in forms inaccessible to sorbents. Acidification of the environment resulting from external factors may result in the increased migration of these components in the subsoil.
When choosing a material useful for the removal of contaminants involved in the oxidationreaction reactions (e.g. nitrates, nitrites, chlorinated hydrocarbons) the ORP should be analyzed. It measures the tendency of a substance to obtain electrons and be reduced (Rajib et al. 2019). The runoff water contains both nitrates and short-lived nitrites, which are considered to be extremely mobile forms of nitrogen in the soil/water environment due to their high solubility and low affinity to the surface of ground particles. In this context, it is likely that ZVI will stimulate the oxidation-reduction processes of these compounds. The properties of the remaining materials do not indicate enhancement of these processes.

One of the processes included in the broadly understood sorption is ion exchange, the measure of which can be the CEC. According to Petersen et al. (1996), the CEC is strongly correlated with the specific surface area. However, no correlation between $\mathrm{S}_{\mathrm{BET}}$ and CEC was observed for the tested materials. Zeolite and silica spongolite are characterized by significant values of this parameter. Due to the negative charge of the zeolite surface (substitution of $\mathrm{SiO}_{4}$ by $\mathrm{AlO}_{4}^{-}$), it is a commonly used material for removing contaminants from solutions by ion exchange, while the use of silica spongolite is less widespread. The negative charge of silica spongolite, diatomite and halloysite may come from the $\mathrm{SiO}-\mathrm{H}$ group on the surface, because all these materials contain $\mathrm{SiO}_{2}$ in their oxide composition $(3.5 \%, 59.5 \%$ and $51.0 \%$ respectively). However, the $\mathrm{CEC}$ value and $\mathrm{SiO}_{2}$ content were not correlated quantitatively. Although this feature is mostly considered as positive, the ion exchange processes can be undesirable in treating the runoff water generated in cold regions. This is related to the potential intermittent release of the previously immobilized contaminants due to deicing salts, and more specifically the $\mathrm{Na}, \mathrm{Mg}$ and $\mathrm{Ca}$ ions, present in the runoff water.

Theoretically, the best treatment results should be obtained for the fine-grained materials, containing a high proportion of clay and organic parts. Similar relationships have also been observed under laboratory and field conditions, including the studies by Yong and Mulligan (2004) and Kumar et al. (2019). This is primarily due to the positive correlation between the size of the solid particles and their specific surface. On the other hand, considering only the unit volume of the runoff water that can be treated as it flows through a treatment zone filled with reactive 
material, the potentially most desirable material would be the one with the highest water transmission. Additionally, in the so-called infiltration systems such as soakaways, the water has to be stored immediately after rainfall and then systematically discharged into the surrounding soil. In this case, the essence is the porosity of the backfill material,; therefore, e.g. coarse gravel, pea gravel or 4/40 aggregate material are commonly used for this purpose (Pazwash, 2016). The reactive materials were assessed on the basis of the value of hydraulic conductivity determined under saturated conditions. The materials tested cannot be used as separate materials for filling the storage zone of infiltration systems (e.g. soakaways). Nevertheless, the values of this parameter are greater than the minimum hydraulic conductivity values of soils in the subsoil in the area where soakaways and other infiltration systems are used $-2.0 \cdot 10^{-6}$ $\mathrm{m} / \mathrm{s}$ (Schueler 1987, Pazwah 2016). Therefore, the analyzed materials can be used as one of the elements of the systems between the storage zone and the surrounding soils. It must be emphasized that this parameter significantly affects the possibility of using a given material in infiltration systems (e.g. soakaways, infiltration ditches and basins). However, the ability to drain water through the systems that additionally perform the function of runoff water treatment is not the only significant property. It cannot be unequivocally stated that with increase of the value of hydraulic conductivity the suitability of materials for use in treatment systems decreases. However, greater flow rate through the treatment zone potentially shortens the time of contact between the material and the contamination and thus the time of treatment processes. Therefore, the most challenging optimization task faced by the designer is to select a material that is equally sufficiently well-permeable and supporting of the treatment processes.

It should be noted that the hydraulic conductivity of a porous medium to a large extent also depends on its grain-size and particle compaction. According to the calculations performed by Mumford et al. (2013), a decrease in grain-size below $0.5 \mathrm{~mm}$ leads to a rapid increase of the capillary rise value $\left(h_{c}\right)$. In consequence, coarser materials should be considered for application in permeable treatment zones located in cold regions. This is due to the fact that the water remaining in the system during the winter affects the hydraulic conductivity of the treatment zone before it is completely melted. Conversely, according to Kumar et al. (2019), particle size may influence the adsorption kinetics; higher values of the kinetic rate constant were observed for materials characterized by smaller particles.

According to the subdivision given by Wiłun (1987), all materials tested are uniformly grained $\left(\mathrm{C}_{\mathrm{U}}\right.$ in the range from 1 to 5$)$, while on the basis of $\mathrm{C}_{\mathrm{U}}$ and $\mathrm{C}_{\mathrm{C}}$ reactive materials can be considered as mono-fraction. However, taking into account the criteria set by the filter materials by AWWA (2002), the particle size distribution of the materials is variable, because $C_{U}$ is greater than 1.7. The exception is $\mathrm{ZVI}\left(\mathrm{C}_{\mathrm{U}}=1.33\right)$, which meets the criterion for high-density materials $\left(\mathrm{C}_{\mathrm{U}}<2.2\right)$. At the same time, activated carbon, zero-valent iron, zeolite, and silica spongolite meet the criterion referring to diameter $\mathrm{d}_{10}$, which should be in the range of 0.35 to $0.65 \mathrm{~mm}$ for sand filters, 0.6 to 1.6 for anthracite filters and 0.18 to 0.6 for high-density materials (AWWA 2002). Diameter $\mathrm{d}_{10}$ was smaller for limestone and halloysite and larger for diatomite than the recommended values. From the application point of view of materials used as a filter bed, it is preferable to use the homogeneous materials with coefficient of heterogeneity of $\mathrm{C}_{\mathrm{U}}$ less than 1.7 for the light materials with specific density greater than $1.4 \mathrm{Mg} / \mathrm{m}^{3}$ (organic materials such as activated carbon) and the mineral materials with specific density greater than $2.5 \mathrm{Mg} / \mathrm{m}^{3}$, and of $\mathrm{C}_{\mathrm{U}}$ less than 2.2 for the materials with specific density greater than $3.8 \mathrm{Mg} / \mathrm{m}^{3}$ (e.g. ZVI) (AWWA 2002). This criterion is only met by zeolite and zero-valent iron.

An important role in the flow of polluted water is also played by the hydrophobicity of porous materials, which is defined as their tendency to repel water molecules from each other. In an unsaturated medium, the flow is the result of gravity and interfacial pressure differences, which depend on the wetting properties, but also on pore geometry (Bachmann et al., 2007). The application of hydrophilic materials is particularly justified when the degree of saturation of the medium changes due to the weather conditions. This results from the fact that in contrast to hydrophobic materials, water flows first through small pores and not through large pores (Wang et al. 2000, Hallet et al. 2011). Conversely, the hydrophobic nature of the materials can 1) induce the development of preferential flow paths, consequently limiting the contact of contaminated waters with reactive materials and reducing the intensity of 
the treatment processes taking place (Ritsema and Dekker, 2000), 2) change the soil water dynamics, 3) decrease the infiltration rate (Hallett et al. 2011), and 4) cause the occurrence of fingering (Wang et al. 2000). This feature is important when predicting the water flow through the treatment layer in the first phase of the runoff occurring just after a period of drought. The material hydrophobicity tests did not indicate a potential problem with the infiltration of runoff water after drying of the materials, e.g. during a rainless period of high temperatures. All materials are hydrophilic, only activated carbon showed a longer droplet penetration time compared to other materials. This may be due to the presence of both hydrophilic and hydrophobic sites on the surface of activated carbon (Groszek and Partyka, 1993). It should be emphasized that the hydrophobicity of the materials used to build systems based on the filtration of the runoff water can be increased due to their long-term contact with oil derivatives, which are apolar particles. Given the above, it can be concluded that the hydrophilic nature of all analyzed materials will not negatively affect the water flow through the newly built-in layer of reactive material.

To sum up, it should be stated that the reactive materials tested can be assessed as good or moderately good materials in terms of their application in the treatment zones of the runoff water from urbanized areas (more specifically from road infrastructure). However, despite their earlier use in water and wastewater treatment, further research should take into account the influence of external factors (e.g. temperature, geochemistry, large loads of dissolved salt) on the stability of the treatment processes.

\section{CONCLUSIONS}

The assessment of the suitability of reactive materials for their application in the runoff water treatment technologies should be carried out on the basis of both the properties of the materials and the contaminants to be treated. Only the knowledge of these two characteristics allows for drawing the conclusions about the potential interactions between the contaminants and solid particles. Firstly, the conducted analyses allow assuming that due to the most extensive specific surface area and developed surface area of micro- and mesopores, the largest amount of contaminants may be removed via adsorption on activated carbon and halloysite. The average pore diameter of zeolite, limestone sand, silica spongolite and halloysite may imply good adsorption kinetic characteristics of these materials. However, after being adsorbed in micropores, contaminants may block other contaminants from accessing the pores of all reactive materials tested. Secondly, the high values of $\mathrm{pH}$ of active carbon, ZVI, limestone sand and silica spongolite may suggest the dominant role of heavy metal precipitation in the runoff water treatment. Additionally, ammonium ions will be released in a gaseous form of ammonia under alkaline conditions. Thirdly, the values of hydraulic conductivity allow considering the analyzed materials as fillers of treatment zones enhancing the removal of contaminants from the runoff water in infiltration systems. Eventually, the assessment of the application potential of reactive materials taking into account their physicochemical and hydraulic parameters indicated activated carbon, together with silica spongolite and zeolite (among mineral materials), as the materials that best meet the analyzed criteria.

\section{REFERENCES}

1. Ahmed M.A., Ali S.M., El-Dek S.I., Galal A. 2013. Magnetite-hematite nanoparticles prepared by green methods for heavy metal ions removal from water. Materials Science and Engineering: B, 178(10), 744-751.

2. ASTM D7100 - 11. 2020. Standard test method for hydraulic conductivity compatibility testing of soils with aqueous solutions.

3. AWWA 2002. Standard for Granular Filter Material. American Water Works Association ANSI/AWWA B100-09.

4. Bachmann J., Deurer M., Arye G. 2007. Modeling water movement in heterogeneous water-repellent soil: 1. Development of a contact angle-dependent water-retention model. Vadose Zone Journal, 6, 436-445.

5. Carman P.C. 1937. Fluid flow through a granular bed. Transactions of the Institute of Chemical Engineers London, 15, 150-156.

6. Doerr S.H., Shakesby R.A., Walsh R.P.D. 2000. Soil water repellency: its causes, characteristics and hydrogeomorphological significance. Earth - Science Reviews, 51, 33-65.

7. Dullien F.A.L. 1979. Porous media fluid transport and pore structure. Academic Press, New York.

8. Feng N., Ghoveisi H., Bitton G., Bonzongo J.-C.J. 
2016. Removal of phyto-accessible copper from contaminated soils using zero valent iron amendment and magnetic separation methods: assessment of residual toxicity using plant and MetPLATETM studies. Environmental Pollution, 219, 9-18.

9. Figarska-Warchoł B., Stańczak G., Rembiś M., Toboła T. 2015. Diatomaceous rocks of the Jawornik deposit (the Polish Outer Carpathians): petrophysical and petrographical evaluation. Geology, Geophysics and Environment, 41(4), 311-331.

10. Fronczyk J., Mumford K.A. 2019. The impact of temperature on the removal of inorganic contaminants typical of urban stormwater. Applied Sciences, 9(7), 1273.

11. Fronczyk J. 2017. Artificial road runoff water treatment by a pilot-scale horizontal permeable treatment zone. Ecological Engineering, 107, 198-207.

12. Gillham R.W., O’Hannesin S.F., 1994. Enhanced degradation of halogenated aliphatics by zero-valent iron. Groundwater, 32(6), 958-967.

13. Groszek A., Partyka S. 1993. Measurements of hydrophobic and hydrophilic surface sites by flow microcalorimetry. Langmuir, 9, 2721.

14. Gruszecka-Kosowska A., Baran P., Wdowin M., Franus W. 2017. Waste dolomite powder as an adsorbent of $\mathrm{Cd}, \mathrm{Pb}(\mathrm{II})$, and $\mathrm{Zn}$ from aqueous solutions. Environmental Earth Sciences, 76, 521.

15. Hallett P.D., Bachmann J., Czachor H., Urbanek E., Zhang B. 2011. Encyclopedia of Agrophysics, Springer.

16. Head K., Epps R. 2011. Manual of soil laboratory testing. Vol. II: Permeability, shear strength and compressibility test. Whittles Publishing, Dunbeath Mill.

17. Hilliges R., Schriewer A., Helmreich B. 2013. A three-stage treatment system for highly polluted urban road runoff. Journal of Environmental Management, 128, 306-312.

18. Huang W., Yu X., Tang J., Zhu Y., Zhang Y., Li D. 2015. Enhanced adsorption of phosphate by flowerlike mesoporous silica spheres loaded with lanthanum. Microporous and Mesoporous Materials, 217, 225-232.

19. Inglezakis V.J., Fyrillas M.M., Stylianou M.A. 2018. Two-phase homogeneous diffusion model for the fixed bed sorption of heavy metals on natural zeolites. Microporous and Mesoporous Materials, 266, 164-176.

20. Khorshidi M., Lu N. 2017. Quantification of exchangeable cations using soil water retention curve. Journal of Geotechnical and Geoenvironmental Engineering, 7, 04017057.

21. Kłapyta Z., Żabiński W. (Ed.) 2008. Mineral sorbents of Poland. AGH University of Science and Technology Press, Cracow.
22. Kozeny J. 1927. Über kapillare Leitung der Wassers im Boden. Sitzungsber. Akademie der Wissenschaften Wien, 136, 271-306 (in German).

23. Kumar P.S., Korving L., Keesman K.J., van Loosdrecht M.C., Witkamp G.J. 2019. Effect of pore size distribution and particle size of porous metal oxides on phosphate adsorption capacity and kinetics. Chemical Engineering Journal, 358, 160-169.

24. Lodeiro P., Barriada J. L., Herrero R., De Vicente, M. S. 2006. The marine macroalga Cystoseira baccata as biosorbent for cadmium (II) and lead (II) removal: kinetic and equilibrium studies. Environmental Pollution, 142(2), 264-273.

25. Matusik J. 2014. Arsenate, orthophosphate, sulfate, and nitrate sorption equilibria and kinetics for halloysite and kaolinites with an induced positive charge. Chemical Engineering Journal, 246, 244-253.

26. Mumford K.A., Rayner J.L., Snape I., Stark S.C., Stevens G.W., Gore D.B. 2013. Design, installation and preliminary testing of a permeable reactive barrier for diesel fuel remediation at Casey Station, Antarctica. Cold Regions Science and Technology, 96, 96-107.

27. Nawrot N., Wojciechowska E. 2018. Assessment of trace metals leaching during rainfall events from building rooftops with different types of coverage-case study. Journal of Ecological Engineering, 19(3), 45-51.

28. Parylak K., Zięba Z., Bułdys A., Witek K. (2013) Weryfikacja wyznaczania współczynnika filtracji gruntów niespoistych za pomocą wzorów empirycznych w ujęciu ich mikrostruktury. Architectura - Acta Scientiarum Polonorum, 12(2), 43-51 (in Polish).

29. Pawluk K., Fronczyk J. 2015. Evaluation of single and multilayered reactive zones for heavy metals removal from stormwater. Environmental Technology, 36(12), 1576-1583.

30. Pazwash H., 2016. Urban storm water management. CRC Press, Taylor \& Francis Group, Boca Raton.

31. Petersen L.W., Moldrup P., Jacobsen O.H., Rolston D.E. 1996. Relations between specific surface area and soil physical and chemical properties. Soil Science, 161(1), 9-21.

32. PN-EN ISO 17892-3:2016-03 Geotechnical investigation and testing. Laboratory soil tetesting of soil. Part 3: Testing theDetermination of specific density.

33. PN-EN ISO 17892-4:2017-01 Geotechnical investigation and testing. Laboratory soil tetesting of soil. Part 4: Determination of particle size distribution.

34. Radziemska M. 2018. Study of applying naturally occurring mineral sorbents of Poland (dolomite halloysite, chalcedonite) for aided phytostabilization of soil polluted with heavy metals. Catena, 163, 123-129. 
35. Radziemska M., Mazur Z. 2017. Chemical composition of spring rapeseed grown in copper-contaminated soil amended with halloysite and zeolite. Journal of Ecological Engineering, 18(2), 38-43.

36. Rajib M., Parveen M., Oguchi C.T. 2019. A rapid technique for measuring oxidation-reduction potential for solid materials. Journal of Science, Technology and Environment Informatics, 07(01), 510-516.

37. Ritsema C.J., Dekker L.W. 2000. Preferential flow in water repellent sandy soils: principles and modeling implications. Journal of Hydrology, 231-232, 308-319

38. Roberts F.J., Carbon B.A. 1971. Water repellence in sandy soils of southwestern Australia: I. Some studies related to field occurrence. Division of Plant Industry CSIRO (Australia), Field Station Record, $10,13-20$.

39. Schollenberger C.J., Dreibelbis E.R. 1930) Analytical methods in base-exchange investigations on soils. Soil Science, 30(3), 161-174.

40. Schueler T.R., 1987. Controlling urban runoff: a practical manual for planning and designing urban BMPs. Washington Metropolitan Water Resources Planning Board, Washington.

41. Shimizu Y., Ateia M., Yoshimura C. 2018. Natural organic matter undergoes different molecular sieving by adsorption on activated carbon and carbon nanotubes. Chemosphere, 203, 345-352.

42. Slater J.C. 1964. Atomic radii in crystals. The Journal of Chemical Physics, 41(10), 3199-3204.
43. Stokes D.J. 2008. Principles and practice of variable pressure environmental scanning electron microscopy (VP-ESEM). John Wiley \& Sons, Chichester.

44. Tawfik D.S., Viola R.E. 2011. Arsenate replacing phosphate: alternative life chemistries and ion promiscuity. Biochemistry, 50(7), 1128-1134.

45. Tran H.N., You S.-J., Hosseini-Bandegharaei A., Chao H.-P. 2017. Mistakes and inconsistencies regarding adsorption of contaminants from aqueous solutions: A critical review, Water Research, 120, 88-116.

46. Valencia A., Ordonez D., Wen D., McKenna A.M., Chang N.B., Wanielista M.P. 2020. The interaction of dissolved organic nitrogen removal and microbial abundance in iron-filings based green environmental media for stormwater treatment. Environmental Research, 109815.

47. Wang Z., Wu Q. J., Wu L., Ritsema C.J., Dekker L.W., Feyen J. 2000. Effects of soil water repellency on infiltration rate and flow instability. Journal of Hydrology, 231, 265-276.

48. Wiłun Z. 1987. Zarys geotechniki, Komunikacji i Łączności Publisher, Warsaw (in Polish).

49. Yong R.N., Mulligan C.N. 2004. Natural attenuation of contaminants in soils. Lewis Publisher, Boca Raton.

50. Xu D., Lee L.Y., Lim F.Y., Lyu Z., Zhu H., Ong S.L., Hu J. 2020. Water treatment residual: A critical review of its applications on pollutant removal from stormwater runoff and future perspectives. Journal of Environmental Management, 259, 109649. 